Çukurova Üniversitesi Mühendislik Mimarlık Fakültesi Dergisi, 32(4), ss. 127-134, Aralık 2017

Çukurova University Journal of the Faculty of Engineering and Architecture, 32(4), pp. 127-134, December 2017

\title{
Momente Maruz Kazıkların Nümerik Olarak İncelenmesi
}

\author{
Gökhan ALTAY*1, Cafer KAYADELEN ${ }^{1}$ \\ ${ }^{\text {I} O s m a n i y e ~ K o r k u t ~ A t a ~ U ̈ n i v e r s i t e s i, ~ M u ̈ h e n d i s l i k ~ F a k u ̈ l t e s i, ~ I ̇ n s ̧ a a t ~ M u ̈ h e n d i s l i g ̆ i ~ B o ̈ l u ̈ m u ̈, ~}$ \\ Osmaniye
}

\section{Özet}

Geliş tarihi: 16.10.2017～Kabul tarihi: 19.12.2017

Zemin mekaniği ve geoteknik mühendisliğinde kazıklı temellerin kullanımının önemi son yıllarda artmaktadır. Taşıma gücü zayıf zeminlerde, taşıma gücü ile ilgili yetersizliği ortadan kaldırmak için tercih edilen kazıklar aynı zamanda sızdırmazlık perdeleri, zemin tutma perdeleri gibi amaçlar için de kullanılmaktadır. Kazıklar genelde düşey yönlü kuvvetlere maruz kalırlar fakat bazen yatay yüklere ve yatay düzlemde momente de maruz kalabilirler. Yükleme tipleri kazıklarla ilgili davranışın anlaşılması ve buna bağlı olarak mühendislik tasarımlarının ortaya çıkmasında çok önem arz etmektedir.

Bu çalışmada sonlu elemanlar yöntemini kullanan ANSYS paket programı vasıtasıyla kazık üzerinde moment yüklerinin etkisini göstermek amacıyla üç boyutlu bir model oluşturulmuştur. Bu amaçla, kazıklar farklı çaplarda ve uzunluklarda modellenmiştir. Kayma gerilmeleri ve kazık üzerindeki belirli bir noktanın deformasyonları moment etkisi altında, farklı çaplarda ve uzunluklarda modellenen kazıklar üzerinde incelenmiştir.

Anahtar Kelimeler: ANSYS, Sonlu elemanlar yöntemi, Kazıklı temeller, Nümerik analiz

\section{Numerical Investigation of Piles Subjected to Moment}

\begin{abstract}
The importance of usage of pile foundation is increasing in soil mechanics and geotechnical engineering in recent years. The pile foundations are used to eliminate inadequacies related to bearing capacity of soils. In addition, the piles are used for the purposes such as sheet pile and sealing sheet piles. Piles are usually exposed to normal forces but sometimes they can be exposed to lateral loads and moments in horizontal plane. These types of loadings are quite important for engineering designs related to piles.

In this paper a three-dimensional model established by using finite element based software ANSYS program to demonstrate the moment effects on piles. For this purpose, piles are modelled with different diameters and lengths. The shear stress occurred on the pile surface and deformation changes of a certain area investigated by the effect of moment applied on piles with having different diameters and lengths. Finally, significant rotation was seen on moment loaded piles and shear stress occurred between pile-soil interface.
\end{abstract}

Keywords: ANSYS, Finite elements method, Pile foundations, Numerical analysis

*Sorumlu yazar (Corresponding author): Gökhan ALTAY, gokhanaltay@osmaniye.edu.tr 


\section{GíRiş}

Geoteknik mühendisliğinde kazık temeller gün geçtikçe daha da önem kazanmaktadır. Gerek yüksek yapılar gerekse yapı temellerinin oturduğu zayıf zeminlerden dolayı kazıklı temellere ihtiyaç duyulmaktadır.

Zeminin ve kazığın çeşidine göre uygulanan kazık temelde, kazıklar farklı yüklere maruz kalabilirler. Genel itibariyle düşey yükler altında çalışan kazıklar bunun yanında bazen yatay yükler ya da moment etkisine maruz kalabilirler. Zaman zaman bu yüklerin ikisine birden, hatta bazen üçüne birden karşı koymaya çalışan kazıklar tasarımlarda kullanılabilirler.

Sonlu elemanlar son yıllarda hızla gelişen bir metot olup aynı zamanda kazık temelin analizlerinde de kullanımının yaygınlaştığı görülmektedir. Bu yöntemle modellenmek istenen kazıkların tasarımı, malzeme özellikleri, malzemeyi zorlayııı etkenler ve iç kuvvetler sonlu elemanlar yaklaşımı ile rahatlıkla tasarlanabilmektedir. Ayrıca literatürde çokça model deneylerden ve arazi deneylerinden elde edilen verilerin sonlu elemanlar yöntemiyle bulunan verilerle karşılaştırılmasında uygun sonuçların bulunduğu görülmektedir.

Sheil ve McCabe [1] yaptıkları çalışmada kazık temellerin açısal distorsiyonunu bir software ile nümerik olarak incelemiştir. Analiz sonuçlarının literatürde yapılan çalışmalarla uyumlu olduğunu belirtmişlerdir.

Yang ve Jeremik [2] tekil bir kazığın elastikplastik zeminde davranışını incelemek amacıyla nümerik bir çalışma yapmışlardır. $\mathrm{Bu}$ amaçla düzgün dane dağılımına sahip kum zemin, kil zemin ve her iksini de içeren tabakalı zemin üstünde analizler yapmışlardır. Sonuç olarak yapılan üç boyutlu nümerik analizlerin literatürden elde edilen verilerle uyumlu olduğunu, özellikle de kum zeminde analiz sonuçlarının literatürden alınan verilerle oldukça yakın olduğunu bulmuşlardır.
Dai ve arkadaşları [3] bazı kabuller yaparak kazıklı temellerin statik ve dinamik rijitliklerini nümerik çözümlerle hesaplamışlardır. Daha sonra bazı denklemler önererek, deneysel sonuçları bu denklemlerle karşılaştırmışlardır. Sonuç olarak önerilen denklemlerin oldukça güvenilir sonuçlar verdiğini göstermişlerdir.

Wulandari ve Tjandra [4] yumuşak zemin üzerine oturan kazıklı radye temelleri PLAXİS programı ile 2 boyutlu olarak analiz etmişlerdir. Analizlerde kullanılan kazık sayısını artırarak oturmaları incelemişlerdir. Sonuç olarak kazık sayısındaki artışın oturmaları azalttığını fakat belirli bir oturmadan sonra kazık sayısındaki artışın oturmaları azaltmadığını göstermişlerdir. $\mathrm{Bu}$ yüzden kullanılacak olan kazık sayısının optimum olması gerektiğini bu sayede en ekonomik çözümün elde edilebileceğini belirtmişlerdir.

Elwakil ve Azzam [5] kazıklı radye temel sistemi üzerinde nümerik ve deneysel çalışmalar yapmışlardır. Kazık boyunun ve kazıkların karelajının, bir kazığın üzerine gelen nihai yük ile ilişkisini incelemişlerdir. Sonuç olarak kazık boyunun ve kazık sayısının azalması durumunda radye temel tarafından taşınan yükün arttığını tespit etmişlerdir.

Jozefiak ve arkadaşları [6] ABAQUS paket programı kullanarak oluşturdukları model kazıklı temellerin taşıma gücü ve oturma değerlerini, CFA kazıklarının kullanılmış olduğu bir zeminde karşılaştırmış ve sonuçların oldukça uyumlu olduğunu bulmuşlardır.

Hasan ve Samadhiya [7] geosentetik donatı kullanarak laboratuvarda yaptıkları model deney sonuçlarını, PLAXIS 3D paket programında modelleyerek birtakım analizler yapmışlardır. Sonuç olarak geosentetik donatının kazığın taşıdığı nihai yük ve rijitliğini arttırdığını tespit etmişlerdir.

Kayadelen ve Altay [8] ANSYS workbench ile 3 boyutlu olarak modelledikleri ve analizlerini yaptıkları dinamik kompaksiyonun sonucunda elde ettikleri grafiklerde ağırlık-deformasyon ve 
yükseklik-deformasyon sonuçlarının yaklaşık olarak lineer olduklarını tespit etmişlerdir. Ayrıca ANSYS ile yapılan bu analizlerin yine literatürle oldukça uyumlu olduğu tespit edilmiştir.

Altay ve Kayadelen [9] ANSYS programını kullanarak kaya düşmelerine karşı kullanılan toprak dolgu setlerin tasarımı ile ilgili yaptıkları çalışmalarında daha önce literatürde yapılmış olan arazi deneylerini doğrulamış ve daha sonra parametrik çalışma yapmışlardır. Nümerik analizlerde ANSYS programından elde edilen sonuçların oldukça tutarlı olduklarını bulmuşlardır.

$\mathrm{Bu}$ çalışmada, moment etkisi altında tekil bir kazığın üzerinde meydana gelen kayma gerilmeleri ve kazık üstünde bir noktada meydana gelen deformasyonlar incelenmiştir. İnceleme için sonlu elemanlar yöntemi kullanan ANSYS paket programı kullanılmıştır. Analizlerde kazık üç boyutlu olarak modellenmiş ve "Static Structural" analiz sistemi kullanılmıştır.

\section{NÜMERİK ANALİZ}

Nümerik analizler sonlu elemanlar yöntemini kullanan ANSYS (Workbench) programı ile gerçekleştirilmiştir. Programın "tasarım" modülüyle tek kazık ve zemin ortamı 3 boyutlu olarak modellenmiştir ve daha sonra zemin ve kazık için malzeme modeli seçilerek malzeme parametreleri girilmiştir. Şekil 1'de kazık ve zemin ortamı 3 boyutlu olarak gösterilmiştir.

Ayrıca Şekil 1'de kazığa uygulanan moment gösterilmiştir. Zemin ortamı 20 m'lik bir küp olarak tasarlanmıştır. Bu boyutlar seçilirken sınır etkileri dikkate alınmıştır.

Şekil 2'te $40 \mathrm{~cm}$ çapında ve $15 \mathrm{~m}$ uzunluğundaki tekil kazığın modeldeki görüntüsü verilmiştir. Şekil 3 ve Şekil 4'te de çapları sırasıyla $80 \mathrm{~cm}$ ve $100 \mathrm{~cm}$ olan kazıklar gösterilmiştir. Ayrıca Şekil 2, 3 ve 4'e bakıldığında moment etkisi altında bu kazıklarda meydana gelen maksimum ve minimum kayma gerilmeleri de gösterilmektedir.

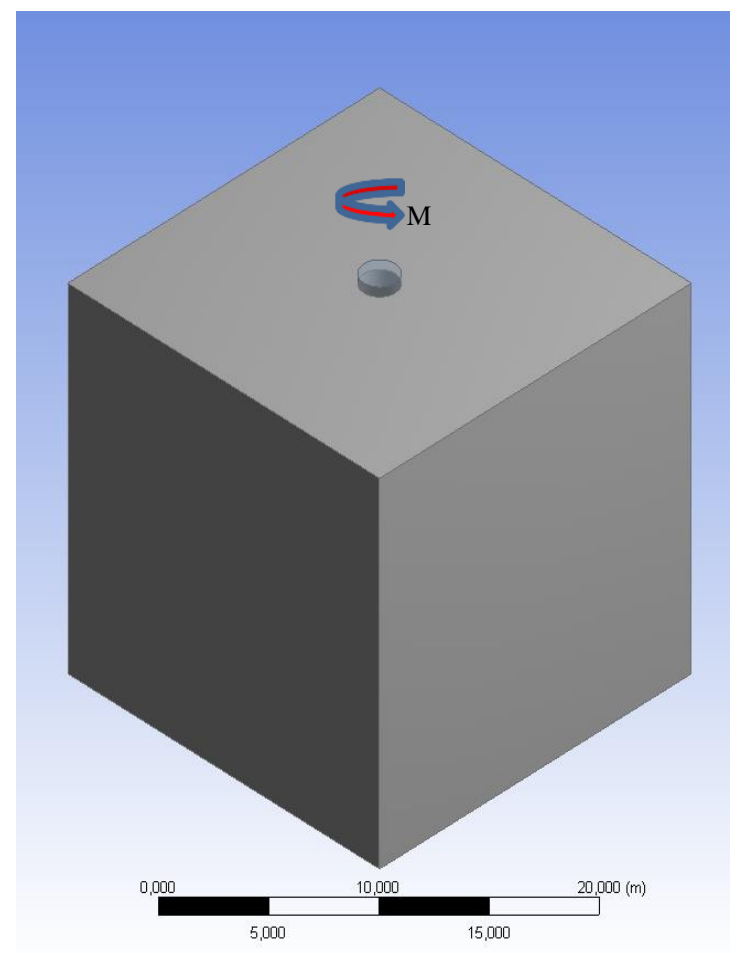

Şekil 1. Kazık ve zemin ortamının 3 boyutlu görüntüsü

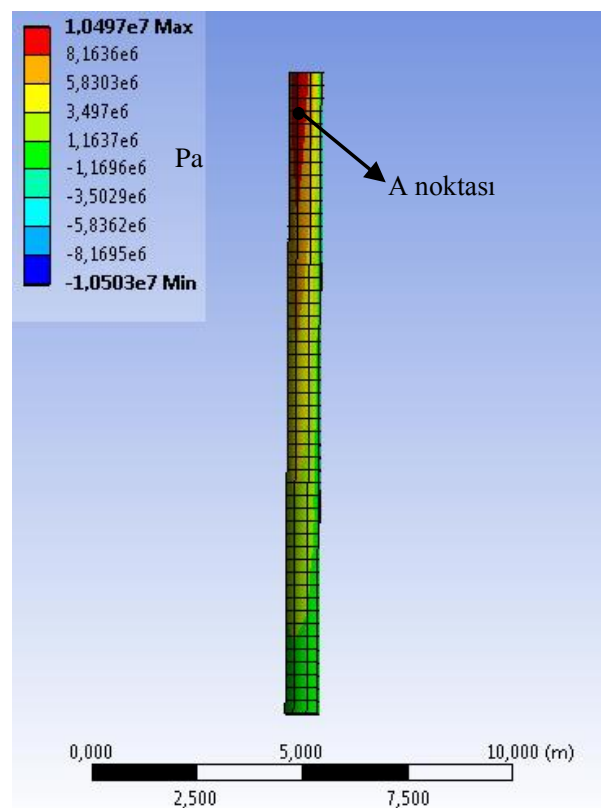

Şekil 2. Çap1 $40 \mathrm{~cm}$ boyu $15 \mathrm{~m}$ olan kazığın kayma gerilmesi dağılımları 
Analizlerde beton kazık kullanıldığı için kazık elemanının malzeme özellikleri olarak beton malzemesinin parametreleri girilmiştir (Çizelge 1).

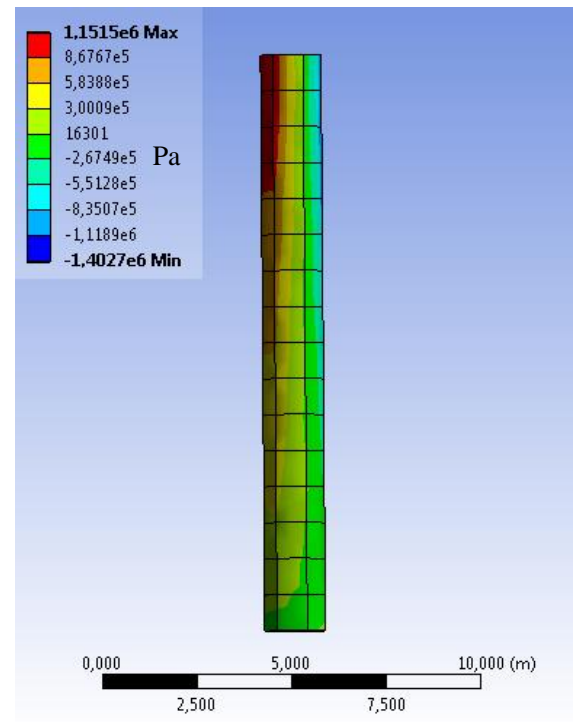

Şekil 3. Çapı $80 \mathrm{~cm}$ boyu $15 \mathrm{~m}$ olan kazı̆̆ın kayma gerilmesi dağılımları

Çizelge 1. Kazık için kullanılan beton malzemesinin özellikleri

\begin{tabular}{|l|c|c|}
\hline Malzeme Parametresi & Birimi & Değeri \\
\hline Yoğunluk & $\mathrm{kg} / \mathrm{m}^{3}$ & 2300 \\
\hline Elastisite Modulü & $\mathrm{MPa}$ & 30000 \\
\hline Posisson Oran1 & - & 0,18 \\
\hline Esneklik Modulü & $\mathrm{MPa}$ & 15625 \\
\hline Kayma Modulü & $\mathrm{MPa}$ & 12712 \\
\hline
\end{tabular}

Zemin modeli olarak drucker-prager kullanılmıştır. Modelde kullanılan zemin parametreleri ise Çizelge 2'de verilmiştir.

Çizelge 2. Zemin ortamı için kullanılan malzemenin özellikleri

\begin{tabular}{|l|c|c|}
\hline Malzeme Parametresi & Birimi & Değeri \\
\hline Yoğunluk & $\mathrm{kg} / \mathrm{m}^{3}$ & 1700 \\
\hline Elastisite Modulü & $\mathrm{MPa}$ & 40 \\
\hline Posisson Oranı & - & 0,30 \\
\hline Esneklik Modüü & $\mathrm{kPa}$ & 33333 \\
\hline Kayma Modulü & $\mathrm{kPa}$ & 15385 \\
\hline Tek Eksenli Basma Dayanımı & $\mathrm{kPa}$ & 150 \\
\hline Tek Eksenli Çekme Dayanımı & $\mathrm{kPa}$ & 50 \\
\hline İki Eksenli Basma Dayanımı & $\mathrm{kPa}$ & 200 \\
\hline
\end{tabular}

Şekil 5'de farklı çaplara sahip kazıkların moment kayma gerilmesi grafiği verilmiştir. Grafiğe bakıldığında kazık çapı küçüldükçe meydana gelen kayma gerilmelerinin arttığı görülmüştür. Ayrıca çap $80 \mathrm{~cm}$ ve $100 \mathrm{~cm}$ olan kazıklarda meydana gelen maksimum kayma gerilmeleri değerlerinin birbirine yakın çıktığı görülmektedir. $40 \mathrm{~cm}$ çapındaki kazığın yüzeyinde oluşan maksimum kayma gerilmelerinin diğer kazıklardan daha büyük olduğu görülmektedir.

Nümerik analizlerde moment yükü altında 3 farklı çapta ve $15 \mathrm{~m}$ boyunda kazıklar modellenmiştir. İlk olarak çapı $40 \mathrm{~cm}$ olan kazı̆̆ın, gerilmesi ve maksimum yanal deformasyon değerleri incelenmiştir. Elde edilen deformasyon azerleri kazık yüzeyinde seçilen ve Sekil 2'de noktanın deformasyon değerleridir. yanal deformasyon değerleri için aynı nokta kullanılmıștır.

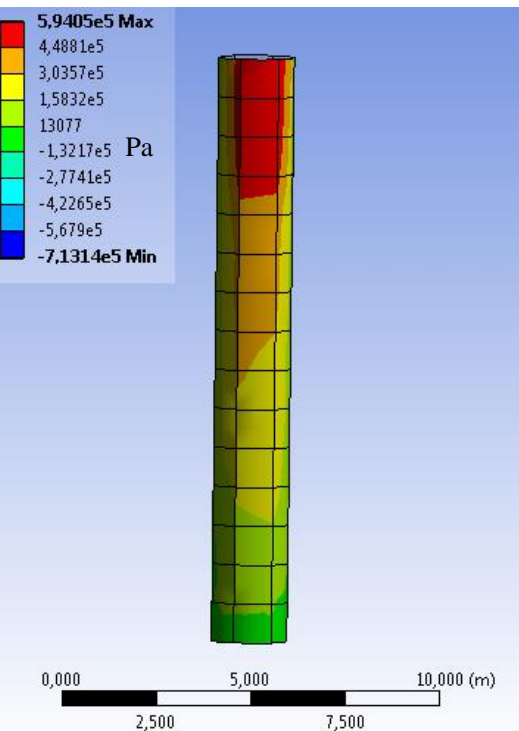

Şekil 4. Çap1 $100 \mathrm{~cm}$ boyu $15 \mathrm{~m}$ olan kazığın kayma gerilmesi dağılımları

\section{BULGULAR}




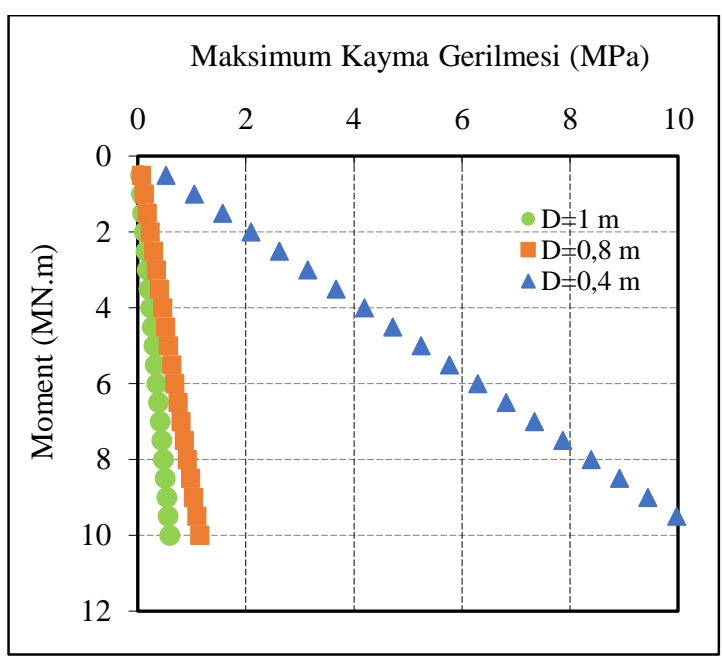

Şekil 5. Farklı çaplara sahip kazıkların kayma gerilmesi-moment grafiğgi

Şekil 6'da ise bu üç farklı çapa sahip $15 \mathrm{~m}$ uzunluğundaki kazıkların üstünde belirli bir noktanın X-ekseni doğrultusunda meydana gelen maksimum yanal deformasyonlarının momentle değişimi gösterilmiştir. Grafikten de görüldüğü üzere kazık çapı azaldıkça meydana gelen maksimum yanal deformasyonlarda artış gözlenmiştir. Aynı şekilde en büyük kazık çapı olan $100 \mathrm{~cm}$ 'lik kazıklarda bu deformasyonlar en az mertebede gerçekleşmiştir.

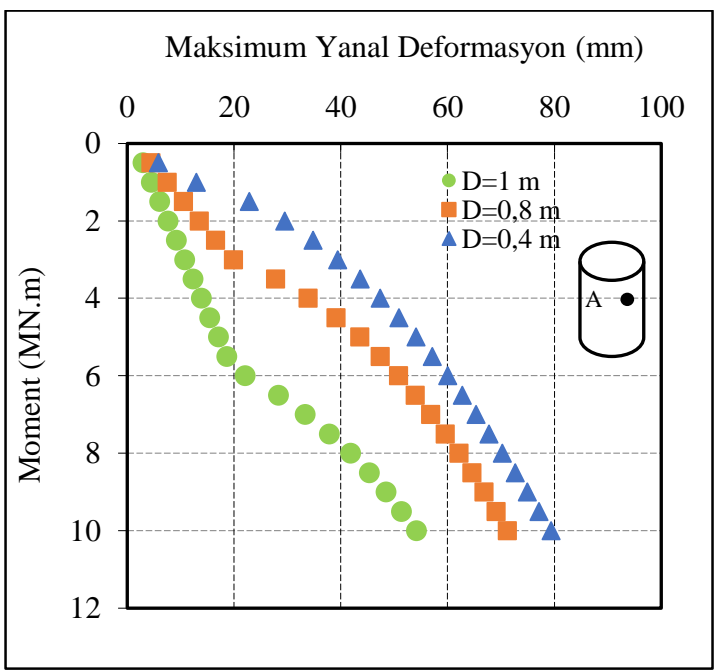

Şekil 6. Farklı çaplara sahip kazıkların deformasyon-moment grafiği
Şekil 7'de farklı çaplara sahip kazıkların maksimum kayma gerilmelerine karşılık gelen maksimum yanal deformasyonları gösterilmektedir. Elde edilen sonuçlarda çapı $100 \mathrm{~cm}$ ve 80 olan kazıkların çapı $40 \mathrm{~cm}$ olan kazığa göre aynı gerilme düzeyinde daha fazla deforme oldukları görülmektedir. Aynı deformasyon değerinde ise çap1 40 olan kazığın diğerlerine göre daha fazla kayma gerilmesine maruz kaldığı görülmektedir.

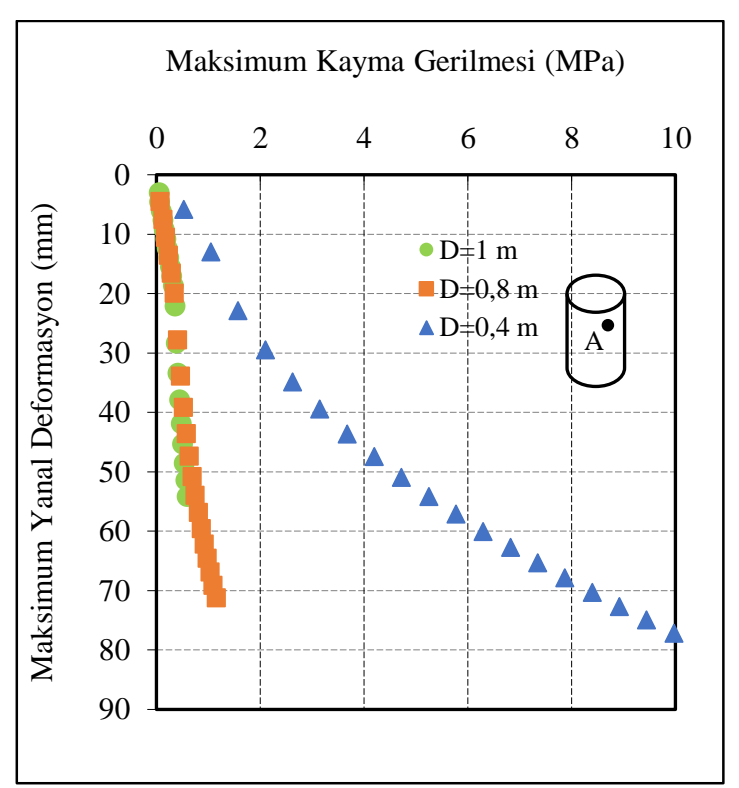

Şekil 7. Farklı çaplara sahip kazıkların kayma gerilmesi-deformasyon grafiği

Şekil 8'de farklı boylara sahip kazıkların moment etkisi altında maksimum kayma gerilmesi değerleri incelenmiştir. Çapı $80 \mathrm{~cm}$ olan bu kazıklar üzerinde yapılan analizlerde belirli bir moment değerinde boy arttıkça maksimum kayma gerilmesinin $\operatorname{arttığı~görülmektedir.~Fakat~}$ maksimum kayma gerilmelerindeki bu artışı çok az olduğu ve en belirgin artışın moment değerinin en fazla olduğu durumda olduğu görülmüştür. Ayrıca maksimum kayma gerilmeleri değerleri arasında çok fazla bir farklılık görülmediği, özellikle de $10 \mathrm{~m}$ ve 15 m'lik kazıklarda bu değerlerin birbirine çok daha yakın olduğu görülmektedir. 


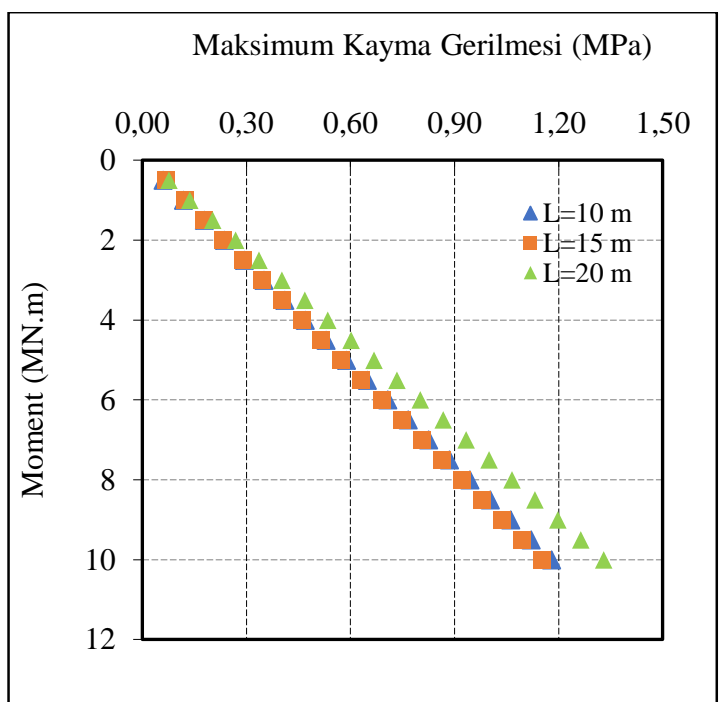

Şekil 8. Farklı boylara sahip kazıkların kayma gerilmesi-moment grafiği

Sekil 9'da $80 \mathrm{~cm}$ çapında farklı boylara sahip kazıkların moment etkisi altında maksimum yanal deformasyon değerleri gösterilmektedir. Her üç kazıkta da momentteki artışa bağlı olarak maksimum yanal deformasyonlar artmıştır. En fazla deformasyona en küçük kazık boyunda rastlanırken en az deformasyona en büyük kazık boyunda gözlenmiştir.

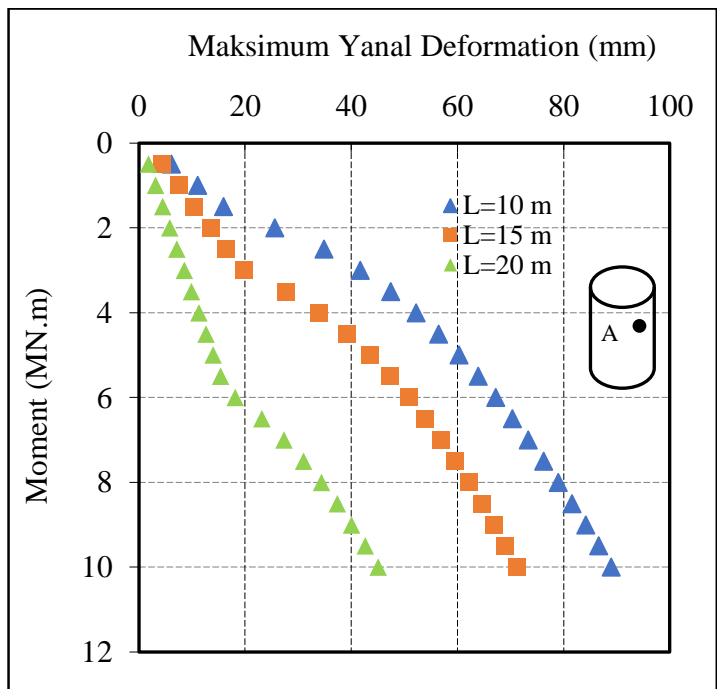

Şekil 9. Farklı boylara sahip kazıkların deformasyon-moment grafiği
Şekil 10'da boyları farklı, çapları aynı ve $80 \mathrm{~cm}$ olan kazıklar üzerinde yapılan analiz sonuçlarına göre maksimum yanal deformasyonlara karşılık gelen maksimum kayma gerilmeleri görülmektedir. $1 \mathrm{MPa}$ kayma gerilmesi altında en fazla deformasyon yaklaşı $80 \mathrm{~mm}$ olarak $10 \mathrm{~m}$ uzunluğundaki kazıkta meydana gelmiştir. Aynı zamanda en az deformasyon ise yaklaşı $1 \mathrm{k} 30 \mathrm{~mm}$ olarak $20 \mathrm{~m}$ uzunluğundaki kazıkta meydana geldiği görülmüştür. Buradan da anlaşılacağ $\breve{g}_{\text {üzere }}$ sabit bir kayma gerilmesi altında boydaki artış deformasyonlarda azalmaya sebep olmaktadır. Bunun tam tersi olarak sabit kayma gerilmesi altında kazık boyundaki azalış deformasyonlarda artmaya sebep olmaktadır.

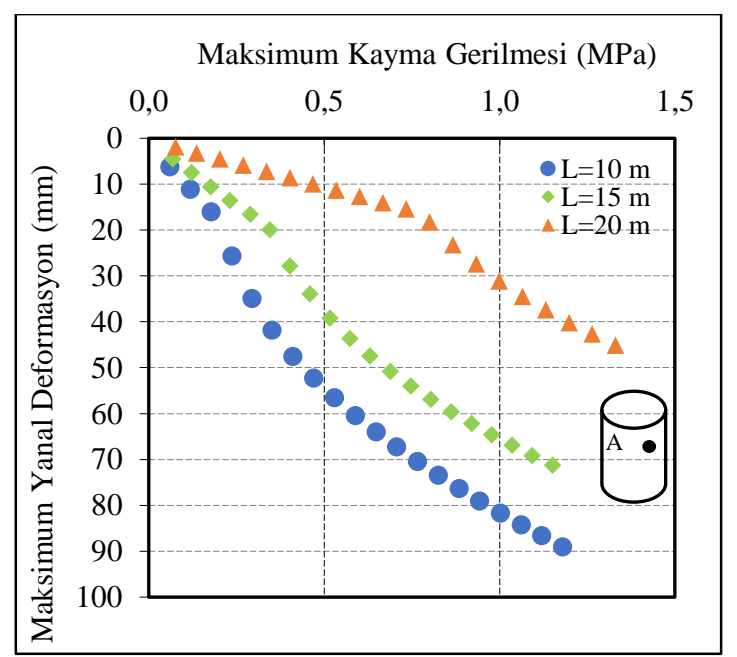

Şekil 10. Farklı boylara sahip kazıkların kayma gerilmesi-deformasyon grafiği

\section{SONUÇLAR}

$\mathrm{Bu}$ çalışmada yapılan nümerik analizlerin sonuçlarına göre, farklı çaplara sahip aynı boydaki kazıklarda momentin artmasiyla maksimum kayma gerilmesi ve maksimum yanal deformasyonların arttığ görülmüştür. Çapları $80 \mathrm{~cm}$ ve $100 \mathrm{~cm}$ olan kazıklarda moment etkisi altında maksimum kayma gerilmeleri birbirine yakın çıkarken çapı $40 \mathrm{~cm}$ olan kazıkta bu gerilmeler çok daha büyük mertebelerde çıkmaktadır. Yine 80 'lik ve 100 'lük kazıklarda maksimum yanal deformasyonlara karşılık gelen maksimum kayma gerilmelerinin 
birbirlerine oldukça yakın değerler çıktığı görülürken 40'lık kazıkta gerilmelerin bu iki kazığa göre daha büyük olduğu görülmektedir.

Aynı çap genişliğine sahip farklı boylarda, moment etkisi altındaki kazıklarda meydana gelen maksimum kayma gerilmelerinin birbirine çok yakın değerler olduğu görülürken, yine aynı kazıklarda moment etkisi altında meydana gelen maksimum yanal deformasyonlarda gözle görülür farklılıkların olduğu tespit edilmiştir. Son olarak boyları farklı çapları aynı olan bu kazıklarda moment etkisi altında oluşan maksimum yanal deformasyonlara karşılık gelen maksimum kayma gerilmelerine bakıldığında, belirli bir deformasyonda kazık boyunun artmasıyla birlikte maksimum kayma gerilmelerinin arttığ görülmüştür.

\section{KAYNAKLAR}

1. Sheil, B.B., McCabe, B.A., 2015. Numerical Modelling of Pile Foundation Angular Distortion. Soils and Foundations, 55(3), 614-625.

2. Yang, Z., Jeremic, B., 2002. Numerical Analysis of Pile Behavior under Lateral Loads. International Journal for Numerical and Analytical Methods in Geomechanics, 02, 1-31.

3. Dai, W., Shi, C., Tan, Y., Rojas F., 2017. A Numerical Solution and Evaluation of Dynamic Stiffness of Pile Groups and Comparison to Experimental Results. Engineering Structures, 151, 253-260.

4. Wulandari, P.S., Tjandra, D., 2015. Analysis of Piled Raft Foundation on Soft Soil using Plaxis 2D. The $5^{\text {th }}$ International Conference of Euro Asia Civil Engineering Forum (EACEF-5), 125, 363-367.

5. Elwakil, A.Z., Azzam, W.R., 2015. Experimental and Numerical Study of Piled Raft System. Alexandria Engineering Journal, 55, 547-560.

6. Jozefiak, K., Zbiciak, A., Maslakowski, M., Piotrowski, T., 2015. Numerical Modelling and Bearing Capacity Analysis of Pile Foundation. XXIV R-S-P Seminar, Theoretical Foundation of Civil Engineering (24RSP) (TFoCE 2015), 111, 356-363.

7. Hasan, M., Samadhiya, N.K., 2017. Performance of Geosynthetic-Reinforced Granular Piles in Soft Clays: Model Tests and Numerical Analysis. Computer and Geotechnics, 87, 178-187.

8. Kayadelen, C., Altay, G., 2016. Numerical Modelling of Dynamic Compaction. $4^{\text {th }}$ International Conference on New Developments in Soil Mechanics and Geotechnical Engineering, 427-432.

9. Altay, G., Kayadelen, C., 2015. Numerical Investigation of Embankments for Protecting Rock Fall. 17 ${ }^{\text {th }}$ International Conference on Geotechnical Engineering (ICGE), 17 (9) Part V, 1033-1038. 
